\title{
Pig acute-phase protein levels after stress induced by changes in the pattern of food administration
}

\author{
C. Piñeiro ${ }^{1}$, M. Piñeiro ${ }^{1 \dagger}$, J. Morales ${ }^{1}$, R. Carpintero ${ }^{2}$, F. M. Campbell ${ }^{3}$, P. D. Eckersall ${ }^{3}$, \\ M. J. M. Toussaint ${ }^{4}$, M. A. Alava ${ }^{2}$ and F. Lampreave ${ }^{2}$ \\ ${ }^{1}$ PigCHAMP Pro Europa S.A. Ctra San Rafael 42, 40006 Segovia, Spain; ${ }^{2}$ Departamento de Bioquímica y Biología Molecular y Celular, Facultad de Ciencias, \\ Universidad de Zaragoza, 50009 Zaragoza, Spain; ${ }^{3}$ Institute of Comparative Medicine, Division of Animal Production and Public Health, Faculty of Veterinary \\ Medicine, University of Glasgow, Bearsden Road, Glasgow G61 1QH, UK; ${ }^{4}$ Department of Veterinary Pathology, Faculty of Veterinary Medicine, Utrecht University, \\ Yalelaan 1, 3508 TD, Utrecht, The Netherlands
}

(Received 19 May 2006; Accepted 18 September 2006)

\begin{abstract}
A total of 240 pigs, 74 days old, half boars and half females, were included in a trial designed to assess the effect of the stress caused by changes in the pattern of food administration on the concentration of acute phase proteins (APP) and productive performance parameters. Half of the animals (pigs fed ad libitum, AL group) had free access to feed, while the rest were fed following a disorderly pattern (DIS group), in which animals had alternating periods of free access to feed and periods of no feeding, when food was removed from the feeder. The periods of free access to feed (two daily periods of 2-h duration) were randomly assigned, and varied from day to day. Total feed supplied per day was identical in both groups, and exceeded the minimal amount required for animals of these ages. Pen feed intake, individual body weights and the main positive pig APP pig major acute phase protein (Pig-MAP), haptoglobin, serum amyloid A (SAA), C-reactive protein (CRP), and the negative APP apolipoprotein A-I (ApoA-I) and transtherytin were determined every 2 weeks during the period 76 to 116 days of age. Animals fed ad libitum had better average daily gain $(A D G)$ than DIS animals in the whole experimental period $(\mathrm{P}<0.01)$ but the differences in $A D G$ were only produced in the two first experimental sub-periods (60 to 74 and 74 to 116 days of age), suggesting that the stress diminished when the animals get used to the DIS feeding. Interestingly differences in ADG between DIS and AL pigs were due to males, whereas no differences were observed between females. The same differences observed for ADG were found for APP. DIS males had higher Pig-MAP concentration than AL males at 74 and 116 days of age, lower ApoA-I concentration at 74 days of age and higher haptoglobin and CRP concentration at 116 days of age $(P<0.05)$. The results obtained in this trial show an inverse relationship between weight gain and APP levels, and suggest that APP may be biomarkers for the evaluation of distress and welfare in pigs.
\end{abstract}

Keywords: acute phase proteins, animal welfare, performance, pigs, stress

\section{Introduction}

Stress can be defined as a state of threat to homeostasis, caused by psychological, environmental or physiological stressors (Chrousos and Gold, 1992). During this state the hypothalamic pituitary adrenal axis (HPA) and the sympathetic nervous system are activated, resulting in physiological changes required to deal with the threat and to restore the internal equilibrium (Black, 2002). It is a well known that pigs are sensitive to stress, and that the growth potential of the current genetic pig lines is often limited by the presence of stressors in the productive system. Previous studies have investigated the influence of

\footnotetext{
${ }^{\dagger}$ E-mail: matildepineiro@pigchamp-pro.com
}

stressors such as hot temperatures or restricted space on pig performance, finding depressed growth and poorer performance in these animals under the effect of such stressors (Hyun et al., 1998a and b; Le Bellego et al., 2002). However, attempts to define measures of stress have been difficult and controversial and no physiological parameter has been successfully used to evaluate all the stress situations studied (Moberg, 1987). The endocrine system was thought to be an appropriate indicator of stress, but plasma cortisol was not consistently changed by different acute stressors (Hicks et al., 1998). Therefore, finding alternative parameters reacting to stressors may be of great value for the objective evaluation and optimisation of productive systems. 
A number of studies indicate that stress alone can induce an acute phase response (for a review see Black (2002)). The acute phase response (APR) is the body's answer to the presence of tissue damage or infection, and consists of a series of physiological responses encountered to repair the damage, recruit host defence mechanism to fight against the threat and finally restore the internal equilibrium. During the APR the concentration of some plasma proteins, named acute phase proteins (APP) is modified. APP are mainly of hepatic origin, and its synthesis is regulated by pro-inflammatory cytokines, mainly interleukin-6 (Baumann and Gauldie, 1994; Gabay and Kushner, 1999). Recent studies suggest that APP may be used to assess stress in farm animals (Murata et al., 2004; Piñeiro et al., 2006). In animals for experimentation, physical and psychological stress elevate APP concentration (Morimoto et al., 1987; Deak et al., 1997) and increases of APP have been also observed in cattle after physical stress (Alsemgeest et al., 1995). An APP response was observed in pigs after road transport, with the magnitude of the APP concentration change apparently related to the quality of transport conditions (Piñeiro et al., 2006). In this study the effect of a changing pattern of food administration was used as a model to induce stress in growing pigs. The concentration of the main pig APP and productive performance were assessed as markers of distressful situations and welfare of pigs.

\section{Material and methods}

Animals and experimental design

Two hundred and forty pigs (LW $\times$ LR), 74 days of age with a body weight of $26.3 \pm 0.39 \mathrm{~kg}$ at the beginning of the experimental period, half boars and half females, were used in the trial. Pigs were moved to the experimental facilities the day before the beginning of the trial, and housed in 24 pens ( 10 animals per pen), 12 pens of males and 12 pens of females, in an environmentally controlled building. The flooring was fully slated, made of concrete slats. Pen dimensions (length $\times$ width) were $2.54 \times 3.00 \mathrm{~m}$, being the space allowance of $0.76 \mathrm{~m}^{2}$ per pig, and each pen was equipped with one three-place concrete feeder, which provided $60 \mathrm{~cm}$ of total trough space. Feeders were located in the front of each pen, on the opposite side of the drinker location. Replicates were randomly divided into two experimental groups. The experimental treatments consisted of pigs fed ad libitum (AL) or disorderly (DIS). Two identical contiguous rooms of 12 pens each, were used for the experiment, and experimental treatments (feeding pattern and sex) were equalised for each room. The group AL always had free access to feed, while DIS feeding consisted of an administration of feed in a disorderly pattern, when during the day, two periods of free access to feed alternated with periods in which food was removed from the feeder. The times of the day at what DIS animals had food available in the feeder (two daily periods of 2-h duration) were assigned each day following a randomly assigned pattern, and varied from day to day. Total feed supplied per day was identical in both groups, and exceeded the minimal amount required for animals of these ages. Diet composition is presented in Table 1.

Pen feed intake and individual body weight (BW) were recorded every 2 weeks (at 74, 88, 102 and 116 days of age). Average daily gain (ADG, g/day), average daily food intake $(\mathrm{Fl}, \mathrm{kg} /$ day), and feed:gain ratio $(\mathrm{FGR}, \mathrm{kg} / \mathrm{kg})$ were calculated for the 2-week sub-periods and the total experimental period (74 to 116 days of age).

At each weight control time-point, blood was sampled from 24 animals of each group (half boars and half females, two samples per pen) by venipuncture of vena cava. Blood sampling was completed in about $0.5 \mathrm{~min}$ per animal, including both holding with a snout rope and sampling. Sera was immediately removed after centrifugation, and kept frozen $\left(-20^{\circ} \mathrm{C}\right)$ until their analysis.

The animal care and experimental procedure used in this study conformed to regulations and guidelines of the Real Decreto Español 223/88 BOE 67: 8509-8511, about the protection of animals used for scientific research.

\section{APP determination}

The concentrations of pig major acute phase protein (PigMAP), haptoglobin, and apolipoprotein $A-I(A p o A-I)$ were determined by radial immunodiffusion (Mancini et al., 1965), in $1 \%$ agarose gel containing specific antiserum. Antisera were raised by subcutaneous injection of the purified proteins in rabbits, as previously described (Lampreave

Table 1 Composition and nutrient content of the experimental diet

\begin{tabular}{lc}
\hline \hline Ingredients $(\mathrm{g} / \mathrm{kg})$ & \\
Barley & 464.2 \\
Maize & 150.0 \\
Wheat & 120.0 \\
Soya-bean meal 44 & 183.4 \\
Sunflower meal 35 & 30.0 \\
Lard & 28.0 \\
CaCO $_{3}$ & 10.3 \\
Dicalcium phosphate & 1.40 \\
Salt & 4.30 \\
L-Lysine liquid & 4.80 \\
Methionine liquide & 0.60 \\
Vitamin/mineral mix & 3.00 \\
Nutrient analysis (g/kg DM) & \\
Net energy (kcal/kg) & 2250 \\
Crude protein & 160.0 \\
Total lysine & 9.40 \\
Crude fat & 29.0 \\
Crude fibre & 46.0 \\
Ash & 45.0 \\
Gross energy (kcal/kg) & 3973 \\
\hline \hline
\end{tabular}

${ }^{\dagger}$ Vitamin/mineral mix provided the following per $\mathrm{kg}$ diet: retinol, $1.575 \mathrm{mg}$; cholecalciferol, $0.013 \mathrm{mg}$; alpha-tocopherol,26.8 mg; phytylmenaquinone, $1 \mathrm{mg}$; thiamine, $1 \mathrm{mg}$; riboflavin, $4 \mathrm{mg}$; pyridoxine, $2 \mathrm{mg}$; cyanocobalamin, $20 \mu \mathrm{g}$; biotin, $10 \mu \mathrm{g}$; niacin, $18 \mathrm{mg}$; Ca-D-pantothenic acid, $10 \mathrm{mg}$; choline, $175 \mathrm{mg}$. Minerals: Fe, $80 \mathrm{mg} ; \mathrm{Zn}, 110 \mathrm{mg} ; \mathrm{Cu}, 90 \mathrm{mg} ; \mathrm{Mn}, 50 \mathrm{mg} ; \mathrm{Co}$, $0.1 \mathrm{mg} ; \mathrm{l}, 1 \mathrm{mg} ; \mathrm{Se}, 0.2 \mathrm{mg}$. 
Pig acute-phase protein levels after food-change stress

et al., 1994; González-Ramón et al., 1995; Carpintero et al., 2005). A serum previously calibrated with the purified proteins was used as standard.

CRP was determined by ELISA as follows: microtitre plates (high bound, Nunc) were coated with phosphoryl choline coupled BSA, and blocked with milk-powder in saline. Samples and standards were diluted in $50 \mathrm{mmol} / \mathrm{I}$ Tris, $0.9 \% \mathrm{NaCl}, 10 \mathrm{mmol} / / \mathrm{CaCl} 2,0.1 \%$ Tween 20 (TBS-CT buffer), and bound CRP was detected using an in-house anti pig CRP monoclonal antibody, followed by a peroxidase-labelled goat anti mouse IgG antiserum (Jackson Immunoresearch Laboratories). All washings and additions of secondary reagents were done in TBS-CT buffer. The ELISA was developed using $50 \mathrm{mmol} / /$ citric acid, $\mathrm{pH}$ 4.0, $0.1 \mathrm{mmol} / \mathrm{l}$ ABTS (2,2 Azino-bis(3-ethylbenzthiazoline6-sulphonic acid), $0.01 \% \mathrm{H}_{2} \mathrm{O}_{2}$ as a colour substrate and the absorbance was read at $405 \mathrm{~nm}$. A porcine serum validated using both a home-made purified porcine CRP preparation as well as the Porcine Acute Phase test kit from Tridelta (Tridelta Development Ltd) was used as an in-plate standard.

Serum amyloid A (SAA) was assayed using the Phase SAA Assay kit (Tridelta Development Ltd), according to the manufacturer's instructions. The concentration of transthyretin was determined by in-house ELISA as previously described (Campbell et al., 2005).

\section{Statistical analysis}

Statistical analysis were performed using the pen as statistical unit for feed intake and feed efficiency, and the animal as statistical unit for body weight evolution, average daily gain and APP concentrations. Productive performance and APP concentration data were analysed by the GLM procedure of Statistical Analysis Systems Institute (1990). Feeding treatment and sex were included in the model as main effects and their interaction (feeding treatment $\times$ sex) were also studied. In the case of productive performance data, the initial body weight was introduced as a covariate and all means were corrected by least squares according to initial weight.

\section{Results}

\section{Productive performance parameters}

The productive performance parameters in the whole experimental period (74 to 116 days of age) and in each subperiod of 2 weeks, are shown in Table 2. BW evolution is outlined in Table 3. Initial BW was similar for both groups of pigs (AL/DIS), but the BW of AL animals was higher than the BW of DIS animals at every subsequent weight control performed. Animals fed AL had better ADG than DIS animals in the whole period $(P<0.05)$ and in the sub-period 74 to 88 days $(P<0.01)$ and a tendency to have better ADG in the sub-period 88 to 102 days $(P<0.1)$. Differences in ADG were associated with both, $\mathrm{FI}$ and FGR. AL animals had higher $\mathrm{Fl}$ in the sub-period 74 to 88 days and better FGR in the sub-period 88 to 102 days.

Significant interactions between treatment and sex were found (Table 2). Differences in ADG between AL and DIS animals in the 74 to 88 days sub-period were due to males (523 v. 398), since females of both groups had similar ADG.

\section{Acute phase proteins}

At the first experimental day (74 days of age) the mean concentrations of the APP studied were similar between treatments. In the AL animals, the positive APP Pig-MAP, haptoglobin and SAA showed its higher mean concentration at this day (74 days of age), decreasing thereafter (Figure 1a). Differences in the behaviour of the APP were found between DIS males and females. In the case of DIS males the concentration of Pig-MAP remained elevated compared with the AL animals, at 88 and 102 days of age

Table 2 Productive performance parameters in the different experimental periods ${ }^{\dagger}$

\begin{tabular}{|c|c|c|c|c|c|c|c|c|c|c|c|c|}
\hline & \multicolumn{12}{|c|}{ Experimental period (days of age) } \\
\hline & \multicolumn{3}{|c|}{$74-88$} & \multicolumn{3}{|c|}{$88-102$} & \multicolumn{3}{|c|}{$102-116$} & \multicolumn{3}{|c|}{$74-116$} \\
\hline & ADG & FGR & $\mathrm{FI}$ & $A D G$ & FGR & $\mathrm{FI}$ & ADG & FGR & $\mathrm{FI}$ & ADG & FGR & $\mathrm{FI}$ \\
\hline \multicolumn{13}{|l|}{$\mathrm{AL}$ group } \\
\hline Male & $523^{a}$ & 1.96 & $0.95^{\mathrm{a}}$ & 577 & 1.91 & 1.05 & 652 & 2.28 & 1.42 & 591 & 2.06 & 1.13 \\
\hline Female & $439^{b}$ & 2.36 & $0.99^{\mathrm{a}}$ & 627 & 2.05 & 1.25 & 681 & 2.26 & 1.5 & 593 & 2.19 & 1.24 \\
\hline \multicolumn{13}{|l|}{ DIS group } \\
\hline Male & $398^{\mathrm{b}}$ & 2.61 & $0.82^{\mathrm{b}}$ & 513 & 2.37 & 1.09 & 676 & 2.32 & 1.51 & 537 & 2.36 & 1.12 \\
\hline Female & $445^{b}$ & 2.11 & $0.91^{\mathrm{ab}}$ & 574 & 2.03 & 1.13 & 656 & 2.4 & 1.52 & 559 & 2.19 & 1.18 \\
\hline s.e. & 22.0 & 0.263 & 0.032 & 32.2 & 0.129 & 0.056 & 31.3 & 0.106 & 0.062 & 21.1 & 0.096 & 0.032 \\
\hline \multicolumn{13}{|l|}{ Significance } \\
\hline Treatment & $* *$ & & $* *$ & $\ddagger$ & $\neq$ & & & & & * & & \\
\hline Sex & & & $\neq$ & $\neq$ & & * & & & & & & * \\
\hline Interaction & $* *$ & & & & $\neq$ & & & & & & & \\
\hline
\end{tabular}

\footnotetext{
a,b Means within a column having a different superscript letter differ significantly $(P<0.05)$.

${ }^{\dagger}$ Abbreviations are: AL: control pigs fed ad libitum, DIS: pigs fed following a disorderly pattern, ADG: average daily gain (g/day), FGR: feed:gain ratio (kg/kg), Fl: average daily food intake(kg/day)

${ }^{\ddagger}$ Approaching significance $(P<0.1)$.
} 
Piñeiro, Piñeiro, Morales, Carpintero, Campbell, Eckersall, Toussaint, Alava, Lampreave

Table 3 Body weight evolution (AL: control pigs fed ad libitum; DIS: pigs fed following a disorder pattern)

\begin{tabular}{lcccc}
\hline \hline & \multicolumn{4}{c}{ Body weight $(\mathrm{kg})$ at age in days } \\
\cline { 2 - 5 } & 74 & 88 & 102 & 116 \\
\hline AL group & & & & \\
$\quad$ Males & $25.1^{\mathrm{b}}$ & $33.7^{\mathrm{a}}$ & $41.8^{\mathrm{a}}$ & $51.2^{\mathrm{a}}$ \\
$\quad$ Females & $28.2^{\mathrm{a}}$ & $32.5^{\mathrm{b}}$ & $41.3^{\mathrm{a}}$ & $51.3^{\mathrm{a}}$ \\
DIS group & & & & \\
$\quad$ Males & $26.3^{\mathrm{b}}$ & $31.9^{\mathrm{b}}$ & $39.2^{\mathrm{b}}$ & $48.9^{\mathrm{b}}$ \\
$\quad$ Females & $25.4^{\mathrm{b}}$ & $32.6^{\mathrm{b}}$ & $40.6^{\mathrm{ab}}$ & $49.9^{\mathrm{b}}$ \\
S.e. & 0.500 & 0.308 & 0.629 & 0.886 \\
Significance & & & & \\
$\quad$ Treatment & & $* *$ & $* *$ & $*$ \\
$\quad$ Sex & $*$ & & & \\
Interaction & $* * *$ & $* *$ & & \\
\hline
\end{tabular}

a,b Means within a column having a different superscript letter differ significantly $(P<0.05)$.

whereas no significant differences between treatments were found in the females (Figure 1a). SAA was also numerically higher in DIS males at 88 days of age (Figure $1 \mathrm{~b}$ ) but the differences were not significant due to the great distribution of values showed by this protein at all sampling time points apart from 116 days of age. DIS males showed higher CRP and haptoglobin mean concentration than AL males at 102 days of age (Figures 1c and $1 \mathrm{~d})$. No significant differences between treatments where observed in the case of females.

The concentration of the negative APP ApoA-I increased slightly with time in AL animals (Figure 2a). Significant differences between groups were observed for males at 88 days of age, having DIS lower main concentration than AL. As in the other APP studied no differences between treatments were found for females. No difference was found in TTR concentration between the AL and DIS groups (Figure $2 b$ )

\section{Discussion}

Novelty has been demonstrated to be a very strong stressor, specially when an animal is suddenly confronted by it (Dantzer and Mormede, 1983) and thus the lack of food in the feeder was expected to cause a stress response in animals used to having food permanently available. In our trial the alteration in the feeding pattern resulted in a loss of weight gain, but although the effect was observed in the whole experimental period (74 to 116 days of age), analysis by sub-periods of 2 weeks, showed that the differences in ADG where due to the two first experimental sub-periods, suggesting that the stress was reduced once the animals got used to the new conditions. Previous works have shown that pig response to repeated stress diminishes with time as the animal adapts to the new situation (Jensen et al., 1996; Schrader and Ladewig, 1999).

Interestingly, significant differences were found in the productive performance depending on sex. Males were affected by the disorder feeding, whereas the growth of females was not significantly different between treatments. Studies with induced stressors have not generally included the effect of sex in the productive performance, however indicators exist that pig stress responses may differ between sexes (Ruis et al., 1997; De Groot et al., 2001). The alterations in the feeding pattern also resulted in changes in the APP concentrations, and differences between sexes observed in the growth efficiency were also found for APP. DIS males showed higher APP levels at 88 and 102 days of age when compared with the control group, whereas no significant differences were observed in the case of females. In the final period (102 to 116 days of age) ADG was similar between control and DIS animals, and in concordance with that, in the last sampling point APP concentration had returned to the range of normal levels, and mean values were similar between treatments.

The good inverse correlation between daily gain and APP concentration levels can be explained because during the APR, pro-inflammatory cytokines do not only affect the liver inducing changes in APP production. These cytokines also exert their action on different targets, leading to a systemic reaction that includes profound metabolic changes. Appetite is suppressed and food intake diminishes, while muscle catabolism is accelerated. An animal in this state of immunological stress is in negative energy balance, and loses rather than gains weight (Johnson, 1997; Spurlock, 1997). Some studies have found an association between elevated pig APP concentration and decreased weight gain (Eurell et al., 1992; Dritz et al., 1996; Clapperton et al., 2005). In this trial, a wide picture of the APP response was obtained, as the study included the main pig positive APP (Lampreave et al., 1994; González-Ramón et al., 1995; Heegaard et al., 1998; Hulten et al., 2003) as well as the negative APP Apo A-I (Carpintero et al., 2005) and transthyretin (Campbell et al., 2005). Some differences were observed in the behaviour of the APP studied. Pig-MAP was the most sensitive protein in the detection of the stress caused by changes in the feeding pattern, as its concentration remained elevated at both, the 88 and the 102 days of age sampling points. In the case of SAA, DIS males have a tendency $(P<0.10)$ to show higher values at 88 days of age, however this protein showed a wide distribution of values, also on the first experimental day, which contributed to the inconclusive nature of the results. In the case of haptoglobin and CRP significant differences were only observed at 102 days of age. These results suggest presence of different regulation patterns between APP in response to stress.

The mechanism of induction of APP after stress is not completely elucidated. Many studies evidence that psychological stressors alone can induce pro-inflammatory cytokine secretion (Nukina et al., 2001; Black, 2002), however the mechanisms and target cells involved in such cytokine production are not known for certain. Neuropeptides, as well as stress hormones, might have a central role in the activation of the APP response elicited by stress (for a review see Black (2002)). 

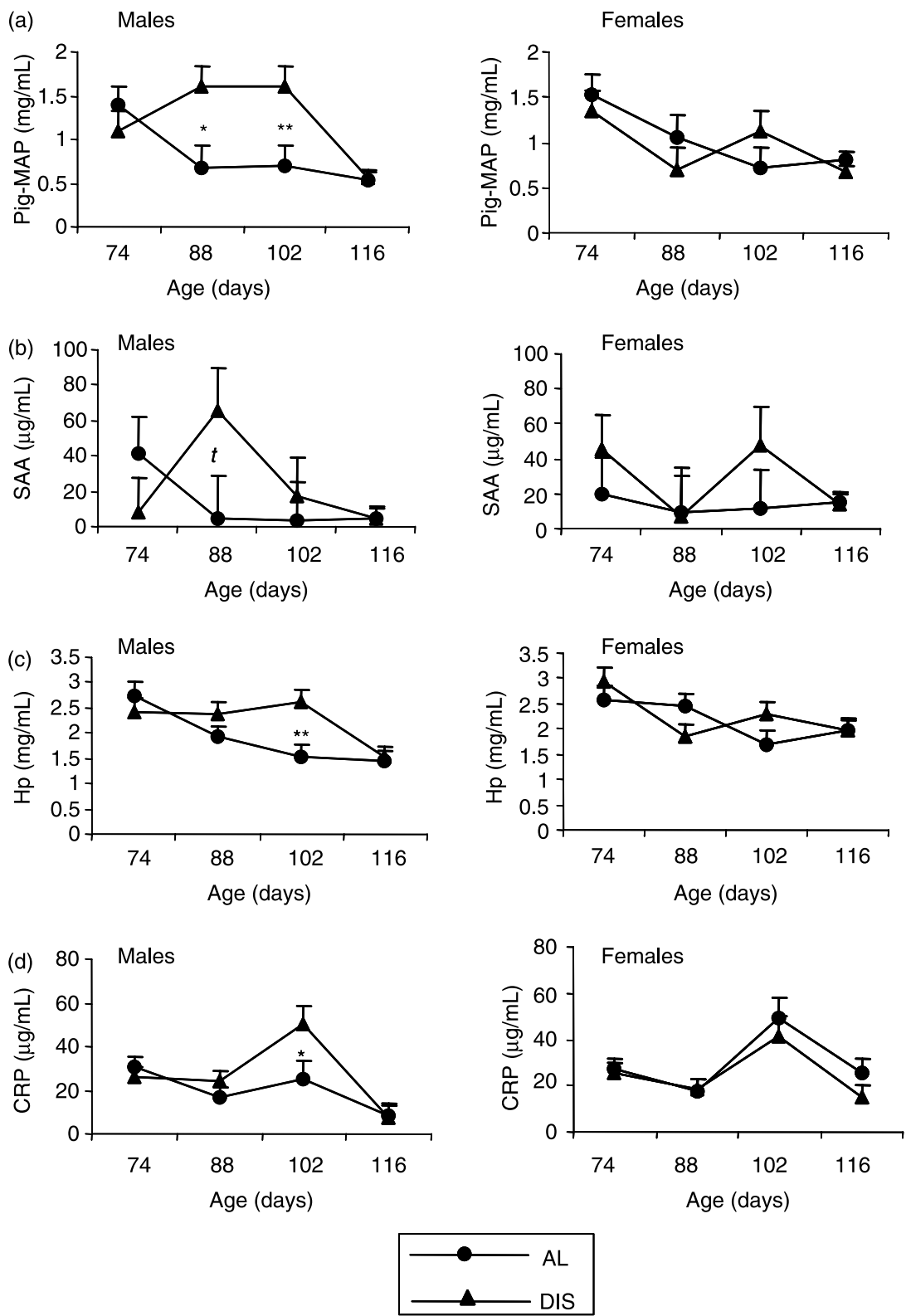

Figure 1 Time course of (a) Pig-MAP, (b) SAA, (c) haptoglobin and (d) CRP concentrations. AL: control animals fed ad libitum. DIS: animals fed following a disorderly pattern of food administration.

Acute phase proteins concentration in the first experimental day were slightly elevated in all treatment groups from the normal levels reached at the end of the trial (decreased in the case of the negative APP Apo A-I). These initial APP levels may have been caused by the stress due to the movement to the new installations, including transport, change of environment and regrouping. Another study from our group showed similar elevations in the concentration of APP 1 day after the entering of the fattening barn, that were greater when pigs were mixed with animals that were previously unknown (Piñeiro et al., 2004). Previous studies have shown that stressors have generally an additive effect (Hyun et al., 1998b); thus the presence of these initial stressors probably enhanced the effect caused by the disorderly feeding. Environmental conditions and handling prior to or during the trial apart from management of food, were identical for all the experimental groups; thus, as initial stressors would be acting for all the groups, including controls, differences observed between DIS and AL males, can be attributed to the management of feeding. Why the disorderly feeding significantly affected males and not females cannot be elucidated from this trial. It is possible that males experienced more stress when exposed to a treatment that may involve dominance and competition, and it is possible that the disorderly feeding might had resulted in an increase of aggressive behaviour that affected more males than females. We could not register data about agonistic behaviour, which would have thrown some light on this subject. However, other studies have found no difference between boars and females in the aggressive behaviour observed 
Piñeiro, Piñeiro, Morales, Carpintero, Campbell, Eckersall, Toussaint, Alava, Lampreave
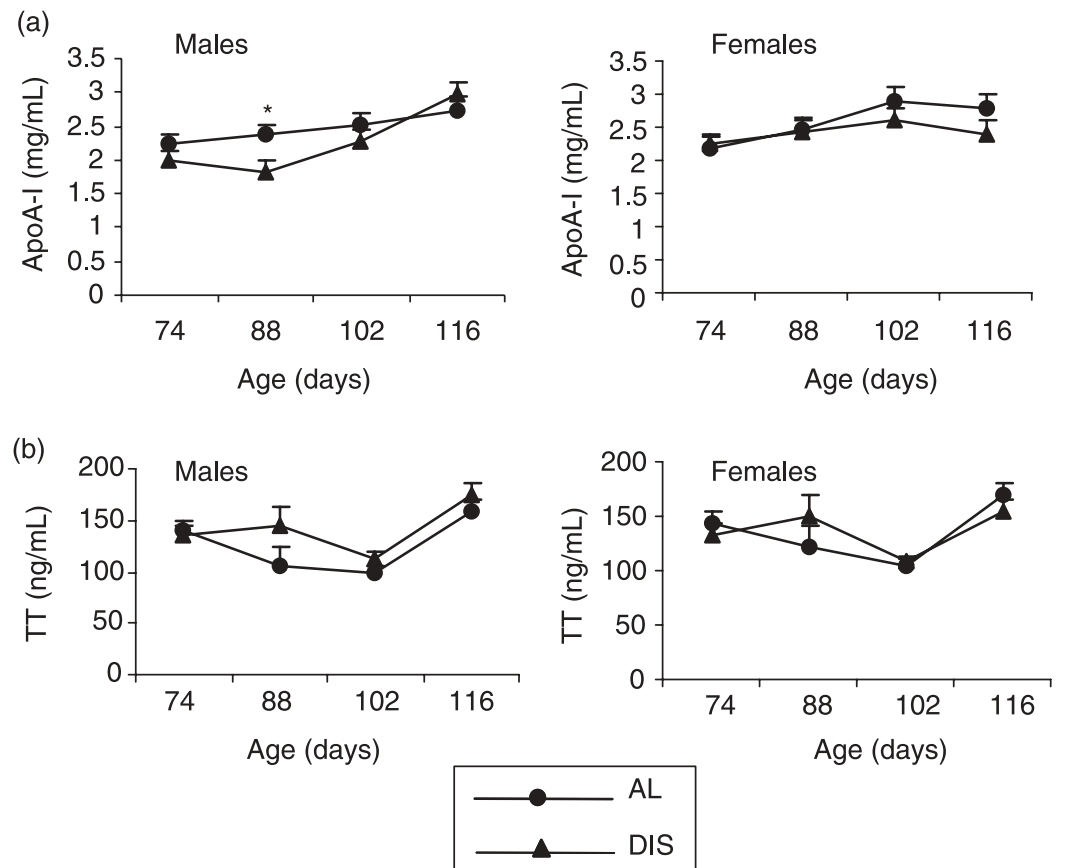

Figure 2 Time course of (a) apolipoprotein-I and (b) transtherytin concentrations. AL: control animals fed ad libitum. DIS: animals fed following a disorderly pattern of food administration.

after regrouping of animals of the same sex (Giersing and Andersson, 1998) and even higher aggressive response in females has been recorded (Stookey and Gonyou, 1994), although this study was performed with barrows and not with intact males, as in our trial. There are however some indicators that the stress response may differ between sexes in pigs, independently of aggressive behaviour. De Groot et al. (2001) found depressed immune function in barrows after mixing, but not in gilts, although agonistic behaviours where similar between sexes. Ruis et al. (1997) showed that after $4 \mathrm{~h}$ isolation the amplitude of the cortisol circadian rhythm was increased in barrows but was unchanged in gilts. Differences in the HPA activation in response to stress have been also found in other species, including rat, human and sheep (Turner et al., 2002; Kajantie and Phillips, 2005, Kudielka and Kirschbaum, 2005; Renard et al., 2005).

Attempts to define measures of stress have been difficult and controversial. Failure to establish an acceptable and general measure of stress has arisen from the inability to solve problems such as lack of a stress response that characterises all types of stressors, inter-animal variability in the biological responses to stress, and no clear correlations between stress measures and meaningful impact on animal welfare (Moberg, 1987). In this sense, it has been suggested that only the stress conditions that lead to pathological states such as immunodepression, failure of reproduction or not normal growth, are undoubtedly affecting animal well-being (Moberg, 1987). According to these criteria APP may be valuable to measure, as they are elevated in distress situations that involve growth loss or activation of immune system. Further studies will be performed to gain more insight about the potential of APP as markers of different causes of stress.

\section{Acknowledgements}

This work was funded by EU Shared Cost Project No. QLK520001-02 219 (APP in pig production) and CDTI Contract No. 000230. Rakel Carpintero holds a fellowship from Fundación Cuenca Villoro. M. Waterston is thanked for assistance in performing immunoassays for SAA and TTR.

\section{References}

Alsemgeest SP, Kalsbeek HC, Wensing T, Koeman JP, van Ederen AM and Gruys E 1995. Influence of physical stress on the plasma concentration of serum amyloid-A (SAA) and haptoglobin (Hp) in calves. The Veterinary Quarterly $17,9-12$.

Baumann H and Gauldie J 1994. The acute phase response. Immunology Today $15,74-80$.

Black PH 2002. Stress and the inflammatory response: a review of neurogenic inflammation. Brain Behaviour and Immunity 16, 622-653.

Campbell F, Waterston M, Andresen LO, Sorensen NS, Heegaard $\mathrm{PMH}$ and Eckersall PD 2005. The negative acute phase response of serum transthyretin following Streptococcus suis infection in the pig. Veterinary Research 36, 657-664.

Carpintero R, Piñeiro M, Andrés M, Iturralde M, Alava MA, Heegaard PMH, Jobert JL, Madec F and Lampreave F 2005. The concentration of apolipoprotein $A-I$ decreases during experimentally induced acute processes in pigs. Infection and Immunity 73, 3184-3187.

Chrousos GP and Gold PW 1992. The concepts of stress and stress system disorders. Overview of physical and behavioural homeostasis. The journal of the American Medical Association 267, 1244-1252.

Clapperton M, Bishop SC, Cameron ND and Glass EJ 2005. Association of acute phase protein levels with growth performance and with selection for growth performance in Large White pigs. Animal Science 81, 213-220.

Dantzer R and Mormede P 1983. Stress in farm animals: a need for re-evaluation. Journal of Animal Science 57, 6-18. 
De Groot J, Ruis MAW, Scholten JW, Koolhaas JM and Boersma WJA 2001. Long-term effects of social stress on antiviral immunity in pigs. Physiology and Behaviour 73, 145-158.

Deak T, Meriwether JL, Fleshner M, Spencer RL, Abouhamze A, Moldawer LL, Grahn RE, Watkins LR and Maier SF 1997. Evidence that brief stress may induce the acute phase response in rats. American Journal of Physiology 273, R1998-2004.

Dritz SS, Owen KQ, Goodband RD, Nelssen JL, Tokach MD, Chengappa MM and Blecha F 1996. Influence of lipopolisaccharide-induced immune challenge and diet complexity on growth performance and acute-phase protein production in segregated early-weaned pigs. Journal of Animal Science 74, 1620-1628.

Eurell TE, Bane DP, Hall WF and Schaeffer DJ 1992. Serum haptoglobin concentration as an indicator of weight gain in pigs. Canadian Journal of Veterinary Research 56, 6-9.

Gabay C and Kushner I 1999. Acute-phase proteins and other systemic responses to inflammation. The New England Journal of Medicine 340, 448-454.

Giersing $M$ and Andersson A 1998. How does former acquaintance affect aggressive behaviour in repeatedly mixed male and female pigs? Applied Animal Behaviour Science 59, 297-306.

González-Ramón N, Alava MA, Sarsa JA, Piñeiro M, Escartín A, García-Gil A, Lampreave $F$ and Piñeiro $A$ 1995. The major acute phase serum protein in pigs is homologous to human plasma kallikrein sensitive PK-120. FEBS Letters 371, 227-230.

Heegaard PM, Klausen J, Nielsen JP, González-Ramón N, Piñeiro M, Lampreave $\mathrm{F}$ and Alava MA 1998. The porcine acute phase response to infection with Actinobacillus pleuropneumoniae. Haptoglobin, C-reactive protein, major acute phase protein and serum amyloid A protein are sensitive indicators of infection. Comparative Biochemistry and Physiology B 119, 365-373.

Hicks TA, McGlone JJ, Whisnant CS, Kattesh HG and Norman RL 1998. Behavioral, endocrine, immune, and performance measures for pigs exposed to acute stress. Journal of Animal Science 76, 474-483.

Hyun Y, Ellis M and Johnson RW 1998a. Effects of feeder type, space allowance, and mixing on the growth performance and feed intake pattern of growing pigs. Journal of Animal Science 76, 2771-2778.

Hyun Y, Ellis M, Riskowski G and Johnson RW 1998b. Growth performance of pigs subjected to multiple concurrent environmental stressors. Journal of Animal Science 76, 721-727.

Hulten C, Johansson E, Fossum C and Wallgren P 2003. Interleukin 6, serum amyloid $A$ and haptoglobin as markers of treatment efficacy in pigs experimentally infected with Actinobacillus pleuropneumoniae. Veterinary Microbiology 95, 75-89.

Jensen $\mathrm{KH}$, Pedersen LJ, Nielsen EK, Heller KE, Ladewig J and Jorgensen E 1996. Intermittent stress in pigs: effects on behavior, pituitary-adrenocortical axis, growth, and gastric ulceration. Physiology and Behaviour 59, 741-748.

Johnson RW 1997. Inhibition of growth by pro-inflammatory cytokines: an integrated view. Journal of Animal Science 75, 1244-1255.

Kajantie E and Phillips DI 2005. The effects of sex and hormonal status on the physiological response to acute psychosocial stress. Psychoneuroendocrinology. In press. doi:10.1016/j.psyneuen.2005.07.002.
Kudielka BM and Kirschbaum C 2005. Sex differences in HPA axis responses to stress: a review. Biological Psychology 69, 113-132.

Lampreave F, Gonzalez-Ramon N, Martinez-Ayensa S, Hernandez MA, Lorenzo HK, Garcia-Gil A and Pineiro A 1994. Characterization of the acute phase serum protein response in pigs. Electrophoresis 15, 672-676.

Le Bellego L, Van Milgen J and Noblet J 2002. Effect of high temperature and low-protein diets on the performance of growing-finishing pigs. Journal of Animal Science 80, 691-701.

Mancini G, Carbonara AO and Heremans JF 1965. Immunochemical quantitation of antigens by single radial immunodiffusion. Immunochemistry 2 , 235-254.

Moberg G 1987. Problems in defining stress and distress in animals. Journal of the American Veterinary Medical Association 191, 1207-1211.

Morimoto A, Watanabe T, Myogin T and Murakami N 1987. Restraint induced stress elicits acute phase responses in rabbits. Pflügers Archiv-European Journal of Physiology 410, 554-556.

Murata H, Shimada N and Yoshioka M 2004. Current research on acute phase proteins in veterinary diagnosis: an overview. The Veterinary Journal 168, 28-40.

Nukina H, Sudo N, Aiba Y, Oyama N, Koga Y and Kubo C 2001. Restraint stress elevates the plasma interleukin- 6 levels in germ-free mice. Journal of Neuroimmunology 115, 46-52.

Piñeiro C, Morales J, Piñeiro M, Lampreave F and Mateos GG 2004. Effects of induced mixing and pen size on performance and serum concentration of acute phase proteins in growing pigs. Journal of Animal Science 82, (suppl. 1) 505 (abstr.).

Piñeiro M, Piñeiro C, Carpintero R, Morales J, Campbell FM, Eckersall PD, Toussaint MJM and Lampreave F 2006. Characterisation of the pig acute phase protein response to road transport. The Veterinary Journal (In press).

Renard GM, Suarez M-M, Levin GM and Rivarola MA 2005. Sex differences in rats: effects of chronic stress on sympathetic system and anxiety. Physiology and Behaviour 85, 363-369.

Ruis MA, Te Brake JH, Engel B, Ekkel ED, Buist WG, Blokhuis HJ and Koolhaas JM 1997. The circadian rhythm of salivary cortisol in growing pigs: effects of age, gender and stress. Physiology and Behaviour 62, 623-630.

Schrader $L$ and Ladewig J 1999. Temporal differences in the responses of the pituitary adrenocortical axis, the sympathoadrenomedullar axis, heart rate, and behaviour to a daily repeated stressor in domestic pigs. Physiology and Behaviour 66, 775-783.

Spurlock ME 1997. Regulation of metabolism and growth during immune challenge: an overview of citokyne function. Journal of Animal Science 75, 1773-1783.

Stookey JM and Gonyou HW 1994. The effects of regrouping on behavioral and production parameters in finishing swine. Journal of Animal Science 72 , 2804-2811.

Turner Al, Canny BJ, Hobbs RJ, Bond JD, Clarke IJ and Tillbrook AJ 2002. Influence of sex and gonadal status of sheep on cortisol secretion in response to ACTH and on cortisol and LH secretion in response to stress: importance of different stressors. Journal of Endocrinology 173, 113-122. 